\title{
A LEITURA COMPREENSIVA COMO UMA HABILIDADE PARA O ENSINO DE CIÊNCIAS: um estudo com professores em formação
}

\author{
Alessandro Augusto de Barros Façanba
}

\section{Resumo}

O estudo revela resultados de uma investigação sobre a leitura compreensiva como uma habilidade necessária ao ensino das ciências na perspectiva da alfabetização científica e seu contexto com a formação de professores. Discute essas categorias à luz da profissionalidade e da educação científica de forma a relacionar a habilidade leitora e sua intersecção como conhecimento profissional. Foi realizada no contexto da formação de professores a partir de um estudo de natureza descritiva e interpretativa em uma universidade pública de referência na formação de professores. Os resultados demonstram uma convergência com os estudos da área da didática das ciências e apontam para a realidade ainda fragilizada do processo de ensino e formação de professores para as ciências evidenciando a necessidade de se pensar o processo formativo articulado com a educação básica e os preceitos de uma alfabetização científica que possibilite inserir a leitura como pressuposto de formação.

Palavras-chave: ensino de ciências; formação de professores; leitura compreensiva.

\section{THE SKILL OF READING IN THE CONTEXT OF SCIENTIFIC EDUCATION: \\ a study with future teachers}

\section{Abstract}

This study reveals the results of an investigation of the understanding of comprehensive reading as a necessary skill in the teaching of science in the perspective of scientific literacy and its context with teacher training. It discusses these categories in the light of professionalism and scientific education in order to relate the reading ability and its intersection as professional knowledge. It was carried out in the context of teacher training based on a descriptive and interpretative study at a public university of reference in teacher training. The results demonstrate a convergence with studies in the area of didactics of the sciences and point to the still fragile reality of the teaching and training process of teachers for the sciences and points to a need to think about the formative process articulated with basic education and precepts of a scientific literacy that makes it possible to insert reading as a training presupposition.

Keywords: science teaching; teacher training; comprehensive reading.

ENTENDER LA LECTURA COMO HABILIDAD PARA LA ENSEÑANZA DE CIENCIAS: un estudio con profesores en formación

Resumen

El estudio revela los resultados de una investigación sobre la comprensión de la lectura integral como una habilidad necesaria para la enseñanza de las ciencias desde la perspectiva de la alfabetización científica y su contexto con la formación del profesorado. Discute estas categorías a la luz de la profesionalidad y la educación científica para relacionar la habilidad de lectura y su intersección como conocimiento profesional. 
Se llevó a cabo en el contexto de la formación del profesorado a partir de un estudio de carácter descriptivo e interpretativo en una universidad pública de referencia en formación del profesorado. Los resultados demuestran una convergencia con los estudios en el área de la enseñanza de las ciencias y apuntan a la realidad aún frágil del proceso de enseñanza y capacitación de maestros para las ciencias y apuntan a la necesidad de pensar en el proceso de capacitación articulado con la educación básica y los estudiantes. preceptos de alfabetización científica que hacen posible insertar la lectura como una condición previa de capacitación.

Palabras clave: Enseñanza de ciencias; Formación de profesores; Lectura comprensiva.

\section{INTRODUÇÃO}

A leitura compreensiva é uma habilidade cognitiva fundamental para a formação dos cidadãos na atualidade. $\mathrm{Na}$ era da informação não basta ler para decodificar símbolos ou reproduzir informações; exige-se um nível de proficiência em leitura que possibilite a compreensão de uma informação em seu contexto, suas aplicações em diversas situações e um comportamento frente ao texto que permita ao leitor autonomia, participação e tomada de decisões.

Compreender o mundo e interpretá-lo a partir da leitura, portanto, é, para além de uma prática de alfabetismo funcional, uma habilidade relacionada ao desenvolvimento cognitivo relativo à tomada de decisão e resolução de problemas e um conhecimento essencial ao processo de ensino e aprendizado seja qual for o conteúdo ensinado. Ler e compreender, para além da mera decodificação de símbolos e de uma linguagem específica, significa uma postura ativa do sujeito perante sua realidade e a manifestação de uma ação consciente através da qual se atribui sentido à informação e se possibilita comunicação, interação, participação e emancipação do indivíduo em relação ao seu contexto (MIRAS; SOLÉ; CASTELLS, 2013; CASSANY; ALIAGAS, 2007; CASSANY, 2003; DE MORENO; DE FORERO, 2007).

Dentre algumas concepções sobre a leitura destaca-se a que a concebe como uma prática social e ativa de significação que estabelece, em decorrência da evolução dos estudos da linguística, a compreensão de que ler consiste em uma ação de interação com a informação visando a construção de representações de sentido, reinterpretações dos significados e contextualização das informações (KLEIMAN, 2004, KOCH, 2016).

Por conseguinte, considera-se a leitura compreensiva como sendo a habilidade de compreensão transliteral a partir da incorporação do contexto do discurso no sentido de extrair do texto suas possibilidades inferenciais a fim de proporcionar tomada de decisões e atuação do sujeito em seu meio social a partir de uma informação expressa (CASSANY, 2006;2010). Correlacionando essa concepção no âmbito do ensino das ciências, é possível estabelecer convergências quando se traça um paralelo entre a noção de leitura compreensiva e o conceito de alfabetização científica adotado pelas matrizes de referência que avaliam a proficiência dos conhecimentos científicos.

Destacando, por exemplo, a designação expressa pelo Conselho Internacional de Ciências (ICSU), uma organização internacional de cooperação para o avanço das ciências cujo espectro de atuação é chancelado pela Sociedade Brasileira para o Progresso da Ciência (SBPC), observa-se que em relação ao conteúdo conceitual sobre a alfabetização científica, se denomina como sendo:

a capacidade de empregar o conhecimento científico para explicar fenômenos científicos, tirar conclusões baseadas em evidências, ter consciência das aplicações científicas no cotidiano e atuar na sociedade de forma crítica (ICSU, 2011, p.10). 
No entanto, entre o conceito e o fenômeno materializado sob a forma de uma habilidade leitora compatível ao aspecto da alfabetização científica, os problemas apresentam-se em torno de cenários preocupantes.

Tomando como referência os índices do Programa Internacional de Avaliação de Estudantes (PISA), em relação à leitura, ainda se constata um cenário preocupante visto que a maioria dos estudantes brasileiros (51\%) se encontra em nível de decodificação leitora denotando um déficit na interpretação, compreensão de sentidos e argumentação, acarretando apenas na compreensão transliteral de um texto (INEP, 2012).

Em decorrência, há uma lacuna também importante no contexto da alfabetização científica como constatados pelos resultados no último exame do PISA em 2015, no qual os estudantes brasileiros obtiveram um desempenho médio da ordem de 401 pontos brutos contra 493 pontos dos estudantes da escrever por extenso (OCDE), caracterizando uma queda de rendimento quando comparado aos anos anteriores (INEP, 2015).

Tais resultados corroboram a compreensão da correlação existente entre a dificuldade de ler um texto de ciências e apropriar-se de seu conteúdo, implicando em uma deficiência no contexto do ensino que, em decorrência de uma dificuldade de compreensão leitora, acarreta dificuldades de aprendizagem de conceitos e interpretação de fenômenos (OLIVERAS; SANMARTÍ, 2009; SANMARTÍ, 2007; JIMÉNEZ-LISO; GUADIX, 2002; MARTÍN-DÍAZ 2013).

Evidências denotam que, pelo fato do aprendizado das ciências não derivar de um conhecimento em si, mas de uma rede de saberes da qual a habilidade leitora faz parte, uma leitura que não promova compreensão da informação acarreta obstáculo à alfabetização científica. Diante dessas constatações e dos problemas que se interseccionam a esse contexto, parte-se da premissa que a formação da habilidade leitora deveria ser um dos pressupostos da formação dos professores de ciências, pois parte das dificuldades de aprendizagem dos estudantes derivam da não compreensão da informação científica em função de uma leitura deficiente que poderia ser minimizada caso essa habilidade fizesse parte das aulas de ciências como conteúdo relacionado ao seu ensino.

Não obstante, a leitura compreensiva precisa ser compreendida como uma habilidade necessária para o exercício da docência na educação científica. Afinal, apesar dos avanços em termos da profissionalização, das estratégias e das metodologias, o processo de formação de professores de ciências ainda apresenta uma série de desafios, dentre os quais, uma reestruturação em nível epistemológico, científico, tecnológico e curricular (KRASILCHIK, 2008; NASCIMENTO; FERNANDES; MENDONÇA，2010; MARTINS; GOUVÊA，2005; DE CARVALHO, 2007).

Esse estudo investiga o processo relacionado à compreensão das informações científicas através da leitura de textos de conteúdo de ciências realizada por futuros professores a fim de se elucidarem as seguintes questões: Quais são as dificuldades encontradas por futuros professores de ciências para lerem compreensivamente um texto de conteúdo científico?; Qual é o conbecimento dos futuros professores sobre a importância da leitura compreensiva no ensino das ciências?; Qual é a compreensão desses futuros professores sobre o conceito de alfabetização científica e sua relação com a leitura compreensiva? 
FUNDAMENTAÇÃO TEÓRICA

\section{LEITURA E FORMAÇÃO DE PROFESSORES DE CIÊNCIAS: UMA INTERSECÇÃO NECESSÁRIA}

No campo da didática das Ciências a leitura se caracteriza como uma habilidade e como conhecimento profissional necessário ao processo de ensino-aprendizagem. Nesse aspecto, a assimilação e internalização dessa habilidade durante a formação dos professores constitui-se como um conhecimento profissional importante à profissionalidade docente.

A compreensão das informações presentes em um texto de natureza científica faz parte da comunicação nas ciências, assimilação de seus conceitos e formação de habilidades relacionadas ao processo cognitivo da educação e alfabetização científica, dentre as quais se destacam a escrita em ciências e a utilização de habilidades no contexto da interpretação dos fenômenos, como por exemplo, classificar, definir, identificar, comparar, dentre outras competências que subsidiam a aprendizagem das ciências naturais. Como destaca Rodriguez (2007): ${ }^{1}$

La lectura y la escritura deben ser consideradas macrohabilidades lingǘsticocognitivas que no involucran únicamente la decodificación de grafías y su adecuada pronunciación o reproducción. Estas actividades exigen al ser humano la necesidad de comprender lo que se lee o, en otras palabras, de tener la capacidad de reconstruir el significado general del texto y de organizar sus ideas para plasmarlas de manera escrita; este acto no sólo debe llevar al lector a tener en cuenta las normas convencionales de la lengua, sino también a entender que el texto escrito tiene (RODRÍGUEZ, 2007, p. 242)

Desenvolver a habilidade da leitura no contexto da formação de professores corrobora não somente para a ampliação do modelo formativo no âmbito de seu desenvolvimento profissional, mas sobretudo consiste em uma ação que, a médio e longo prazo, colabora para uma ressignificação da formação docente no campo do ensino das ciências, pois insere a leitura para além da linguagem e da comunicação, como uma habilidade inerente à compreensão dos conteúdos em função de um processo de alfabetização científica (SANMARTÍ, 2007).

A formação dessa habilidade para a prática docente possibilita, além de uma amplitude de profissionalidade, um aperfeiçoamento do ensino das ciências pois se relaciona aos aspectos da assimilação dos conteúdos em contextos de problematização do ensino, adoção de estratégias de investigação nas aulas de ciências e um alinhamento às práticas voltadas a discussão científica e ao desenvolvimento desse pensamento atrelado à leitura (SANMARTí, 2010).

Afinal, em relação à profissionalização docente as intersecções entre o campo linguístico da leitura compreensiva e a aprendizagem da linguagem científica consolidam-se como uma competência científica necessária ao ensino e aprendizado das ciências principalmente em relação aos conceitos e suas aplicações, as quais se apresentam em textos dessa natureza que precisam ser compreendidos e ressignificados durante as aulas de ciências (JORBA; GOMEZ; PRAT, 2000).

\footnotetext{
1 A leitura e a escrita devem ser consideradas macrossindutivas linguísticas-cognitivas que não envolvam apenas a decodificação das ortografias e sua pronúncia ou reprodução adequadas. Essas atividades exigem que o ser humano entenda o que é lido ou, em outras palavras, ter a capacidade de reconstruir o significado geral do texto e organizar suas ideias para refleti-las por escrito; este ato não deve apenas levar o leitor a levar em conta as normas convencionais da língua, mas também a entender que o texto escrito tem (RODRÍGUEZ, 2007, p. 242)
} 
A leitura, nesse sentido, concilia-se com o chamado letramento científico ${ }^{2}$ a partir da incorporação da habilidade linguístico-cognitiva da leitura no rol dos conhecimentos necessários para se ensinar ciências, pois corresponde não somente como um conhecimento profissional necessário, mas como uma condição essencial para o desenvolvimento do pensamento científico e para o aprendizado dos estudantes (SANMARTÍ 2007; JORBA; GÓMEZ; PRAT 2000; ARCHILA 2012, 2014)

A inserção da habilidade relacionada a leitura compreensiva como um conteúdo de formação para o ensino das ciências, portanto, aprimora a ação docente em termos de uma profissionalidade que possibilite a assimilação de novos símbolos e de linguagens específicas imprescindíveis ao ensino-aprendizagem disciplinar, pois nesse sentido, a habilidade da leitura converge para o desenvolvimento da linguagem como uma forma de comunicação que favorece a compreensão dos sentidos (LEMKE, 2004).

Por consequência, ler de forma compreensiva em aulas de ciências, além de favorecer a prática profissional docente em relação ao processo de educação científica mais eficiente, proporciona ambientes motivadores ao ensino, pois, à medida que se insere a leitura como habilidade e estratégia para se ensinar, se aproxima o conteúdo das ciências do cotidiano, favorecendo assim o aprendizado.

\section{LEITURA COMPREENSIVA E APRENDIZADO DAS CIÊNCIAS}

O aprendizado nas/das? ciências podem ser interpretado a partir do conceito de proficiência associado às habilidades constituintes da alfabetização científica expressas nas matrizes de referência dos exames, pois se configuram como uma expressão do que é esperado para um estudante após passar pelo processo de educação científica. Centrando o olhar sobre esses parâmetros, portanto, é possível estabelecer como habilidades relativas ao aprendizado a capacidade de aplicar o conhecimento científico, utilizar explicações a partir de modelos ou representações, fazer previsões, elaborar hipóteses e interpretar evidências (BRASIL; INEP, 2016).

Por consequência dessas habilidades como categorias explícitas de aprendizagem, é possível relacionar a leitura compreensiva como instrumento de formação e desenvolvimento cognitivo pois, à medida que ler compreensivamente permite realizar inferências, contextualizar fatos e interpretar uma informação em função de sua transliteralidade, a interseção da leitura ao processo de aprendizado das ciências reforça a educação científica em sua plenitude (SANMARTÍ, 2007).

Correspondendo a esse fato, a didática das ciências dispõe de inúmeras evidências que correlacionam o aprendizado dos conteúdos científicos e a interpretação de seus fenômenos ao processo de assimilação da linguagem científica e a aquisição de proficiência leitora. Afinal, a partir da interpretação da informação contida em textos de natureza científica incorporam-se demais habilidades relacionadas ao aprendizado, aplicação dos fenômenos em diversos contextos e aquisição de fundamentos científicos para compreender o cotidiano (IZQUIERDO; ALIBERAS, 2004; IZQUIERDO; ADÚRIZ BRAVO, 2003; SANMARTÍ, 2007).

\footnotetext{
2 O Termo "literacy", do anglo-saxão, não apresenta uma tradução similar para o português, desta forma, em consonância com o relatório do INEP/2006, apresenta-se de modo a designar "alfabetização" científica, uma vez que, aborda o conceito de competência científica, com as dimensões das habilidades, atitudes e competências. No entanto, apesar de contextos distintos, em alguns estudos, o termo é tratado conceitualmente como "letramento científico", mesmo não guardando entre si uma relação linguística e semântica de sinonímia. (TEIXEIRA, 2013)
} 
Evidências presentes em muitos estudos que correlacionam a leitura com a compreensão das ciências demonstram que esta não é somente um instrumento para acesso à informação, mas uma habilidade que promove o desenvolvimento de estruturas mentais e de representações associadas à aprendizagem que estabelece relações de significado e sentido entre o que se lê, se experiencia e se interpreta dos fenômenos naturais. Conforme explica Sanmartí (2010):

La actividad lectora está en la base de muchas estrategias que son básicas para aprender ciencias, ya que posibilita establecer relaciones, comparar, generar preguntas, analizar críticamente, enriquecer el vocabulario, apropiarse de modelos textuales para la escritura (SANMARTÍ, 2010, p. 2).

Consequentemente, a alfabetização científica como finalidade de aprendizado nas ciências passa pela leitura como habilidade para compreender os fenômenos e para apropriar-se ou modificar conhecimentos, afinal implica na aquisição de um conhecimento procedimental capaz de instruir o sujeito para atuar de forma autônoma e consciente com os textos de forma a interagir com a informação e a partir de sua compreensão validar o conhecimento, pois, ao contrário do ensino reprodutor e memorístico que acompanhou a educação científica por muitas décadas, na atualidade se requer do indivíduo a capacidade de pensar cientificamente para tomar decisões e resolver problemas (DA SILVA; BARGALLÓ; PRAT, 2017).

Revela-se portanto, que a partir da leitura nas ciências além da promoção de aprendizagem é possível conciliar a leitura como uma forma de superar visões distorcidas da ciência e suplantar as percepções do senso comum que dificultam a compreensão do cotidiano, pois o texto científico está presente no dia a dia das pessoas em diversos gêneros que vão desde as publicações de divulgação científica até as produções textuais informativas que precisam ser articuladas à compreensão das ciências como forma de se entender o mundo ao redor (JORBA; GÓMEZ; PRAT 2000).

Entretanto, para se inserir a leitura como conhecimento para se ensinar ciências é preciso revelar algumas das questões que envolvem esse contexto principalmente em relação às dificuldades, o saber profissional dos futuros professores e a forma como se lê nas aulas de ciências. Antes de se pensar em uma mudança estrutural de formação é necessário se planejar em torno da realidade que se apresenta.

Nesse sentido, esse estudo revela um cenário acerca desse campo de estudo em um ambiente de formação de futuros professores, a partir do qual é possível traçar algumas constatações e generalidades sobre o papel da leitura nesse contexto específico do ensino das ciências.

\section{METODOLOGIA DO ESTUDO}

O estudo retrata uma investigação realizada com 18 licenciandos do curso de Pedagogia de uma universidade pública da região Nordeste na disciplina de "Metodologia do Ensino das Ciências Físicas e Biológicas". Nesta coorte, $88 \%$ eram mulheres e $12 \%$ homens, com média de idade de 23,55 anos.

Em virtude da natureza descritiva do estudo e do enfoque interpretativo dos dados, optouse pela estratégia de investigação a partir da aplicação de uma prova pedagógica (em anexo) por permitir caracterizar o estudo do estado do conhecimento e das habilidades dos sujeitos envolvidos (CEREZAL; FIALHO, 2010). Além disso, no campo das investigações que envolvem os aspectos cognitivos, as provas pedagógicas representam uma estratégia para a caracterização da atividade 
dos estudantes que permitem conhecer a efetividade do ensino assimilado e servem como parâmetro para o diagnóstico inicial de uma habilidade ou conteúdo (NOCEDO LEÓN, 2002).

Adequando-se aos objetivos, elaborou-se uma prova na qual os licenciandos deveriam responder sobre sua compreensão sobre a leitura compreensiva como habilidade para ensinar ciências, como executavam uma leitura compreensiva de um texto de conteúdo científico e qual a relação entre alfabetização científica e leitura compreensiva. Sua elaboração adequou-se aos objetivos e à natureza do objeto de estudo sob a previsão de se caracterizar as dificuldades do processo de leitura compreensiva de um texto de conteúdo científico, a relação entre a leitura e a alfabetização em ciências de acordo com o seguinte planejamento:

Quadro 1 - Plano da prova pedagógica

\begin{tabular}{|l|l|}
\hline \multicolumn{1}{|c|}{ OBJETIVO } & \multicolumn{1}{c|}{ PERGUNTA } \\
\hline $\begin{array}{l}\text { Identificar o conhecimento sobre o que é a } \\
\text { leitura compreensiva de um texto de conteúdo } \\
\text { científico }\end{array}$ & $\begin{array}{l}\text { O que é ler compreensivamente um texto de } \\
\text { conteúdo científico? }\end{array}$ \\
\hline $\begin{array}{l}\text { Caracterizar as dificuldades de se ler } \\
\text { compreensivamente um texto de conteúdo } \\
\text { científico }\end{array}$ & $\begin{array}{l}\text { Realize a leitura do texto da prova e descreva } \\
\text { as dificuldades para compreensão das } \\
\text { informações contidas }\end{array}$ \\
\hline $\begin{array}{l}\text { Identificar o conhecimento sobre a relação entre } \\
\text { a leitura e a alfabetização científica }\end{array}$ & $\begin{array}{l}\text { O que você compreende como alfabetização } \\
\text { científica e qual é o papel da leitura nesse } \\
\text { processo? }\end{array}$ \\
\hline
\end{tabular}

Fonte: elaborada pelo autor, 2019

Em relação às análises dos dados, definiram-se categorias de acordo com as respostas analisadas e em consonância com os objetivos previamente propostos, agrupadas em tabelas que explicitam os resultados em função do aspecto conceitual sobre leitura compreensiva, da caracterização das dificuldades de se ler compreensivamente um texto de natureza científica e do conhecimento do conceito de alfabetização científica e sua relação com a habilidade leitora (enunciar as categorias). A partir das análises dos dados (descrever como os dados foram analisados), fez-se uma discussão em torno da formação docente dos futuros professores e sua profissionalidade para o ensino das ciências em função da habilidade da leitura compreensiva.

\section{RESULTADOS E DISCUSSÃO}

As primeiras análises referem-se aos dados relativos ao aspecto conceitual da leitura compreensiva e dizem respeito ao objetivo de identificar o conhecimento desse conteúdo na perspectiva dos estudantes de pedagogia. A título de organização dos dados, os mesmos foram tabulados em função de categorias expressas de acordo com o conteúdo das respostas descritas na prova pedagógica tabuladas em função da distribuição de frequência percentual em relação ao número de participantes, conforme a tabela a seguir:

Tabela 1 - Compreensão dos estudantes acerca do aspecto conceitual da leitura compreensiva nas ciências de acordo com o conteúdo das respostas da prova pedagógica 
DOI: $10.12957 /$ teias.2021.52881

\begin{tabular}{c|c|c}
\hline $\begin{array}{c}\text { CONTEÚDO DA RESPOSTA EM FUNÇAO DO } \\
\text { CONCEITO DE LEITURA COMPREENSIVA }\end{array}$ & $\begin{array}{c}\text { NÚMERO DE } \\
\text { ESTUDANTES }\end{array}$ & $\%$ \\
\hline $\begin{array}{c}\text { Define a leitura compreensiva em ciências a partir da } \\
\text { identificação do assunto e das ideias científicas apresentadas }\end{array}$ & 8 & 44,44 \\
\hline $\begin{array}{c}\text { Define a leitura compreensiva em ciências como uma ação para } \\
\text { identificar os conceitos }\end{array}$ & 3 & 16,67 \\
\hline $\begin{array}{c}\text { Correlaciona a leitura compreensiva em ciências com a ideia de } \\
\text { validade da informação em termos científicos e aplicações em } \\
\text { contextos diversos }\end{array}$ & 3 & 16,67 \\
\hline $\begin{array}{c}\text { Não sabe responder } \\
\text { TOTAL }\end{array}$ & 4 & 100 \\
\hline
\end{tabular}

Fonte: elaborada pelo autor, 2019

As respostas não demonstram na sua maioria $(44,44 \%)$ um alinhamento em relação ao conteúdo conceitual expresso pela literatura específica acerca da leitura em ciências como referenciado a partir do marco teórico adotado no estudo, pois, apesar de não designar um conceito absoluto, há um conteúdo invariante adotado pelos pesquisadores da área da didática das ciências que estabelece a leitura compreensiva de textos científicos em torno da interpretação dos fenômenos, capacidade de resolução de problemas de natureza científica, tomada de decisões e inferência de conclusões a partir das informações de um texto (SANMARTÍ 2007; JORBA; GÓMEZ; PRAT 2000; ARCHILA 2012), bem como a elaboração de conclusões em torno de hipóteses e argumentação (SILVA; BARGALLÓ; PRAT, 2017).

No entanto, em consonância com esses mesmos referenciais há em torno das respostas relacionadas à validação de informações e aplicação dos conceitos em contextos diversos $(16,67 \%)$, uma aproximação conceitual com a invariante conceitual esperada, desta forma, mesmo com uma frequência baixa de respostas, há uma convergência com o conhecimento esperado nessa parcela de estudantes, porém, apesar dessa evidência, também se observa em igual representatividade a noção da leitura compreensiva como uma simples ação relacionada a identificação de conceitos $(16,67 \%)$, o que denota uma provável influência da percepção da leitura como uma habilidade decodificadora e não inferencial, uma vez que em termos linguísticos a identificação de uma informação textual sem um apelo inferencial ou de contexto representa uma ação textual de decodificação (CASSANY, 2011; SOLÉ, 2009).

Nesse aspecto, suscita-se uma interpretação desses dados como uma influência do aspecto formativo desses estudantes, pois como são licenciandos de um curso de pedagogia, apesar de não fazer parte do esperado em relação ao processo de formação do leitor, ainda há um forte apelo e heranças de modelos formativos inspirados em concepções leitoras não inferenciais (SOLÉ, 2009). Além disso, como a utilização dos textos de ciências não é uma praxe no contexto da alfabetização, essa lacuna pode significar essa relação com o modelo de formação desses alunos, uma vez que existe uma parcela que sequer respondeu sobre o questionamento na prova pedagógica $(22,22 \%)$.

Com relação ao aspecto relativo às dificuldades encontradas pelos estudantes para a realização da leitura compreensiva, foram determinadas categorias a partir do conteúdo presente 
nos registros relacionados a execução da leitura durante a prova pedagógica e de suas respostas. Os resultados foram tabulados em função do aspecto do conteúdo conforme expresso na tabela a seguir:

Tabela 2 - Categorização relativa às dificuldades para ler compreensivamente um texto científico

\begin{tabular}{c|c|c}
\hline CATEGORLAS & $\begin{array}{c}\text { NÚMERO DE } \\
\text { ESTUDANTES }\end{array}$ & $\mathbf{\%}$ \\
\hline Desconhecimento do conteúdo & 6 & 33,33 \\
\hline Ideias prévias equivocadas sobre o assunto & 5 & 27,78 \\
\hline Dificuldade com termos específicos das ciências & 5 & 27,78 \\
\hline Dificuldade de entender o contexto da informação & 2 & 11,11 \\
\hline TOTAL & 18 & 100 \\
\hline
\end{tabular}

Fonte: elaborada pelo autor, 2019

Em relação as dificuldades descritas pelos estudantes e registradas em seu processo de leitura da prova pedagógica, observam-se que as categorias caracterizam aspectos condizentes com o que se evidenciam em estudos dessa natureza, pois, dentre os aspectos revelados observa-se que as dificuldades convergem em função da natureza da educação científica que os professores experenciaram no decorrer de sua formação (ABREU; BEJARANO; HOHENFELD, 2016) e que se demonstram através do desconhecimento do conteúdo das ciências presentes no texto $(33,33 \%)$, equívocos nas ideias prévias sobre a temática científica $(27,78 \%)$ e o próprio desconhecimento de termos específicos expressos nas informações do texto $(27,78 \%)$.

Ressalta-se que, em relação aos equívocos acerca das ideias prévias, uma dificuldade relacionada ao contexto das concepções alternativas e sua implicação na aprendizagem, pois, a medida que as concepções alternativas se constituem uma construção intelectual para se compreender o mundo e dar sentido aos fatos e fenômenos cotidianos (GIORDAN; VECCHI, 1999), podem internalizar-se como barreiras epistemológicas à aprendizagem ou constituírem erros conceituais que dificultam o aprendizado das ciências (CARRASCOSA ALÍS, 2005).

Tais constatações ratificam-se ao analisar os registros das leituras realizadas nas provas pedagógicas onde demonstra-se, pelos apontamentos relatados, que os estudantes não executam um planejamento para a leitura a fim de traçar um objetivo prévio para a compreensão. Essa execução sem um momento de planejamento prévio é tida pelos estudiosos da temática (SANMARTÍ, 2007; SOLÉ, 2009) como um dos fatores que amplificam as dificuldades de compreensão, pois é justamente na fase prévia à leitura que se traçam hipóteses, antecipações da temática, correlações entre o conhecimento prévio e o científico, além de ser uma fase que estabelece a familiaridade com os elementos textuais gerais.

Dessa maneira corrobora-se a ideia defendida na problematização dessa investigação acerca da necessidade de se inserir a habilidade leitora como um conhecimento necessário à formação dos professores de ciências, pois a partir do aspecto compreensivo de uma informação, é possível ampliar o nível de entendimento dos fenômenos e aprimorar o processo de alfabetização científica 
uma vez que também evidencia uma lacuna na formação conforme pode ser observado no item da prova pedagógica específico a essa questão.

No quesito associado a avaliar o nível de conhecimento dos futuros professores sobre o conceito de alfabetização científica e sua relação com a leitura compreensiva de textos de conteúdo científico, os resultados demonstram uma grande fragilidade no conhecimento conceitual sobre a correlação entre ler para compreender e a alfabetização nas ciências, o que confere um desalinhamento entre o que se encontrou nas respostas e o que é desejado para futuros professores de Ciências.

Tabela 3 - Categorização das respostas acerca da relação entre a alfabetização científica e a leitura compreensiva de acordo com o conteúdo

\begin{tabular}{c|c|c}
\hline CATEGORIAS & $\begin{array}{c}\text { NÚMERO DE } \\
\text { ESTUDANTES }\end{array}$ & $\%$ \\
\hline $\begin{array}{c}\text { Não sabe responder pois desconhece o conceito de } \\
\text { alfabetização científica }\end{array}$ & 11 & $61,11 \%$ \\
\hline $\begin{array}{c}\text { Leitura ajuda na compreensão da ideia de um texto } \\
\text { científico }\end{array}$ & 4 & $22,22 \%$ \\
\hline Leitura a partir de textos de ciências & 3 & $100,67 \%$ \\
\hline TOTAL & 18 & \\
\hline
\end{tabular}

Fonte: elaborada pelo autor, 2019

Em relação ao conhecimento sobre a correlação entre a leitura e a alfabetização científica os dados acima evidenciam uma grande necessidade de se inserir essas discussões na formação de professores, pois as respostam denotam um enorme déficit conceitual.

Afinal, se observa que $61,11 \%$ dos participantes sequer conhecem o significado do que é a alfabetização científica e aqueles que em suas respostas referem conhecer, apresentam em suas versões um conhecimento distorcido visto que para $22,22 \%$ se trata de um conhecimento acessório ao entendimento do texto e 16,67\% confundem como uma modalidade da leitura para textos de ciências, demonstrando uma enorme lacuna acerca desse conceito.

Nesse sentido, os achados corroboram o entendimento de que há um déficit de conhecimento conceitual sobre o que significa alfabetização científica bem como a sua importância no contexto da profissionalidade dos futuros professores de Ciências, pois, à medida que se afasta do conceito $^{3}$, denota uma lacuna da formação desses professores e uma distorção do propósito da educação científica a partir das matrizes de referência adotadas internacionalmente (OCDE, 2012;2015).

Como destacam algumas pesquisas da área da didática das ciências, este aspecto permite inferir o real distanciamento entre as áreas do conhecimento onde ainda é forte a presença de um certo sectarismo entre as áreas das ciências e a linguística e vice-versa corroborando para ratificar

\footnotetext{
${ }^{3}$ Capacidade de empregar o conhecimento científico para explicar fenômenos científicos, tirar conclusões baseadas em evidências, ter consciência das aplicações científicas no cotidiano e atuar na sociedade de forma crítica (ICSU, 2011, p.10).
} 
um modelo segmentado de educação que delega a função de alfabetizar como uma ação distante de educar sob o ponto de vista da ciência e uma falsa impressão de que o conhecimento da leitura não é um instrumento para se alfabetizar cientificamente (SANMARTÍ, 2010; MARQUÉZ;PRAT, 2005; MARBÀ; MÁRQUEZ; SANMARTÍ, 2009).

\section{CONCLUSÕES}

Apesar de não configurar um caráter conclusivo no sentido estrito da extrapolação desses resultados para um universo relativo aos professores de ciências, é possível pontuar algumas especificidades importantes para se entender tanto o contexto dessa investigação através do diálogo que seus resultados fazem com estudos da área da didática das ciências. Em termos das dificuldades apresentadas e evidenciadas pelas categorias de análise, há um nítido distanciamento entre o conhecimento necessário para ensinar ciências em uma perspectiva da alfabetização científica sob o contexto da leitura compreensiva e o que se estabelece como concepção de educação científica por parte desses futuros professores.

Nesse sentido, vale ressaltar como principais dificuldades a ausência de uma formação conceitual em Ciências, a existência de concepções alternativas que se consolidam como obstáculos de aprendizagem e a própria dificuldade da leitura no sentido de determinadas temáticas, o que denota uma lacuna do processo formativo ao mesmo tempo que aponta para a necessidade de uma reformulação curricular, didática e metodológica do processo de formação desses professores.

Considerar esses aspectos peculiares em relação à educação científica, entretanto, não pode servir para uma inferência exclusiva do processo formador, pois, conforme defendido na atualidade, a formação do pensamento científico com finalidade de se formar cidadãos alfabetizados cientificamente deve ser implementada desde o início do processo de formação da educação básica. Um indivíduo que não tem desde os anos iniciais da escolarização um processo voltado para a compreensão das ciências tornar-se-á, independente da sua área de atuação, um sujeito com fragilidades em torno da interpretação de fenômenos científicos que corroboram para uma ausência da relação entre a leitura e esse contexto.

Por fim, não no sentido de concluir, mas de um encaminhamento, cabe à sociedade repensar o seu modelo educacional científico e o processo de inserção de seus cidadãos no universo da ciência, tecnologia e alfabetização científica sob o risco de nos tornarmos uma população à margem da ordem mundial. Quiçá esse processo inicie-se nas escolas o mais precocemente pois escola e universidade precisam dialogar, tanto na formação desses professores como no cenário de atuação desses profissionais.

\section{REFERÊNCIAS}

ABREU, Lenir; BEJARANO, Nelson; HOHENFELD, Dielson. O conhecimento Físico na formação de professores do ensino fundamental I. Investigações em Ensino de Ciências, v. 18, n. 1, p. 23-42, 2016.

ARCHILA, Pablo Antonio. La investigación en argumentación y sus implicaciones en la formación inicial de profesores de ciencias. Revista Eureka sobre Enseñanza y Divulgación de las Ciencias, p. 361-375, 2012.

BRASIL, INEP. Brasil no Pisa 2015-Sumário Executivo. Brasília: INEP, 2016. 
CARRASCOSA ALÍS, Jaime. El problema de las concepciones alternativas en la actualidad (parte I). Análisis sobre las causas que la originan y/o mantienen. 2005.

CASSANY, Daniel. Aproximaciones a la lectura crítica: teoría, ejemplos y reflexiones. Tarbiya: revista de investigación e innovación educativa del Instituto Universitario de Ciencias de la Educación. 2003;(32): 113-32, 2003.

CASSANY, Daniel. Prácticas lectoras democratizadoras. Textos de didáctica de la lengua y la literatura. 2011;(58): 29-40., 2011.

CEREZAL, Julio; FIALLO, Jorge. Cómo investigar en Pedagogía. La Habana: Pueblo y Educación, 2010.

DE CARVALHO, Anna Maria Pessoa. Habilidades de professores para promover a enculturação científica. Revista Contexto \& Educação, v. 22, n. 77, p. 25-49, 2007.

DE MORENO, Stella Serrano; DE FORERO, Alix Madrid. Competencias de lectura crítica: una propuesta para la reflexión y la práctica. Acción pedagógica, v. 16, n. 1, p. 58-68, 2007.

GIORDAN, André; VECCHI, GERARD DE. Los origenes del saber: De las concepciones personales a los conceptos cientificos. 1999.

IZQUIERDO, M.; ALIBERAS, y J. Pensar, actuar i parlar a la classe de ciències. Barcelona: Universitat Autónoma de Barcelona, 2004.

IZQUIERDO-AYMERICH, Mercè; ADÚRIZ-BRAVO, Agustín. Epistemological foundations of school science. Science \& Education, v. 12, n. 1, p. 27-43, 2003.

JORBA, Jaume; GÓMEZ, Isabel; PRAT, Àngels (Ed.). Hablary escribirpara aprender: Uso de la lengua en situación de enseñanza-aprendizaje desde las áreas curriculares: editores, Jaume Jorba, Isabel Gómez y Àngels Prats. Universitat Autònoma de Barcelona, Institut de Ciènces de l'Educació, 2000.

JORGE, Anna Sardà; BARGALLÓ, Conxita Márquez; PUIG, Neus Sanmartí. Cómo promover distintos niveles de lectura de los textos deficiencias. Revista Electrónica de Enseñanza de las ciencias, v. 5, n. 2, p. 290-303, 2006.

International Council for Science [ICSU] (2011). Report of the ICSU ad-hoc review panel on science. Paris: InternationalCouncil for Science. [Disponível em: www.icsu.org]. (Acessado em Janeiro de 2018).

KLEIMAN, Angela B. Abordagens da leitura. Scripta, v. 7, n. 14, p. 13-22, 2004.

KOCH, Ingedore Villaça; ELIAS, Vanda Maria. Escrever e argumentar. São Paulo: Contexto, 2016.

KRASILCHIK, Myriam. Caminhos do ensino de ciências no Brasil. Em Aberto, v. 11, n. 55, 2008.

LEMKE, Jay L. The literacies of science. Crossing borders in literacy and science instruction: Perspectives on theory and practice, p. 33-47, 2004.

LEONTIEV, Alexei Nicolaevich; DUARTE, Manuel Dias. O desenvolvimento do psiquismo. 1978.

MÁRQUEZ, Conxita; PRAT I PLA, Àngels. Leer en clase de Ciencias. Enseñanza de las Ciencias, v. 23, n. 3, p. 431-440, 2005.

MARBÀ, Anna; MÁRQUEZ, Conxita; SANMARTí, Neus. ¿ Qué implica leer en clase deficiencias. Alambique, v. 59, p. 102-111, 2009.

MARTINS, Isabel; GOUVÊA, Guaracira. Analisando aspectos da leitura de imagens em livros didáticos de ciências por estudantes do ensino fundamental no Brasil. Enseñanza de las Ciências, n. Extra, 2005. 
MIRAS, Mariana; SOLÉ, Isabel; CASTELLS, Nuria. Creencias sobre lectura y escritura, producción de síntesis escritas y resultados de aprendizaje. Revista mexicana de investigación educativa, v. 18, n. 57, p. 437-459, 2013.

MOON, Jennifer. We Seek it Here...: A New Perspective on the Elusive Activity of Critical Thinking: a Theoretical and Practical Approach. Higher Education Academy, Education Subject Centre, 2005.

NASCIMENTO, Fabrício; FERNANDES, Hylio Laganá; DE MENDONÇA, Viviane Melo. O ensino de ciências no Brasil: história, formação de professores e desafios atuais. Revista histedbr on-line, v. 10, n. 39, p. 225-249, 2010.

NOCEDO DE LEÓN, Irma et al. Metodología de la investigación social. Editorial Pueblo y Educación. La Habana, 2002.

RODRÍGUEZ, Ada Nelly. Lectura crítica y escritura significativa: Acercamiento didáctico desde la lingüística. Laurus, v. 13, n. 25, p. 241-262, 2007.

SANMARTÍ, Neus. Leer para aprender ciencias. Leer. es, 2010.

SILVA, Márcia Gorette Lima da; BARGALLÓ, Conxita Marquez; PRAT, Begonya Oliveras. Analysis of the difficulties of preservice teachers of chemistry when critically reading a press article. Educação e Pesquisa, v. 43, n. 2, p. 535-552, 2017.

SOLÉ, Isabel. Motivación y lectura. Aula de innovación educativa, v. 179, p. 56-59, 2009.

TEIXEIRA, Francimar Martins. Alfabetização científica: questões para reflexão. Ciência \& Educação (Bauru), v. 19, n. 4, p. 795-809, 2013.

\section{Informações do autor}

Alessandro Augusto de Barros Façanha

Professor Adjunto do Departamento de Educação do Centro de Ensino Superior do

Seridó/CERES/UFRN, Líder do Grupo de Pesquisas em Ensino de Ciências - GPENCI/CNPq, professor do Programa de Pós-Graduação em Química, Rede Nacional/PROFQUI.

E-mail: abfacanha@gmail.com

ORCID: https://orcid.org/0000-0001-8574-4751

Link Lattes: http://lattes.cnpq.br/5040038454192937 